\title{
Discurso referido, gramaticalización y construcción lingüística del texto
}

José Luis Girón Alconchel

\section{OpenEdition}

1 Journals

Edición electrónica

URL: https://journals.openedition.org/cher/3237

DOI: $10.4000 /$ cher.3237

ISSN: 2803-5992

Editor

Presses universitaires de Strasbourg

\section{Edición impresa}

Fecha de publicación: 27 junio 2017

Paginación: 13-33

ISBN: 978-2-86820-961-0

ISSN: 1968-035X

\section{Referencia electrónica}

José Luis Girón Alconchel, «Discurso referido, gramaticalización y construcción lingüística del texto» reCHERches [En línea], 18 | 2017, Publicado el 01 diciembre 2021, consultado el 07 diciembre 2022. URL: http://journals.openedition.org/cher/3237 ; DOI: https://doi.org/10.4000/cher.3237

\section{(c) (i) (2)(2)}

Creative Commons - Atribución-NoComercial-Compartirlgual 4.0 Internacional - CC BY-NC-SA 4.0 https://creativecommons.org/licenses/by-nc-sa/4.0/ 


\section{Discurso referido, gramaticalización y construcción lingüística del texto ${ }^{1}$}

JoSÉ LUIS GIRÓN ALCONCHEL*

Cl discurso referido (DR) es el procedimiento primigenio de introducir la Epalabra de otro en el discurso de uno, y, por ello, uno de los instrumentos principales de la polifonía textual. Voloshinov (1976: 143) lo definió con una precisión que me parece insuperable: el discurso referido es «discurso dentro del discurso y discurso acerca del discurso, enunciado dentro del enunciado y enunciado acerca del enunciado».

Esta definición implica: a) considerar unidades textuales superiores a la oración en el sentido de «más allá» de la oración (una de las acepciones de discurso); pero b) también en el sentido de «más arriba» de la oración (Garrido 2013), porque se considera la enunciación -que es otra de las acepciones de discurso- y el enunciado, «el decir» y «lo dicho»; c) hay una enunciación y un enunciado que citan o refieren y otra enunciación y otro enunciado que son citados o referidos; d) la enunciación y el enunciado que citan incluyen en sí mismos a la enunciación y al enunciado citados («discurso dentro del discurso... enunciado dentro del enunciado«): incluir -«poner algo dentro de otra cosa o dentro de sus límites» (DRAE)-, tratándose de unidades lingüísticas, parece que no puede ser otra cosa que integrar o agregar; pero e) la enunciación y el enunciado que citan también llevan a cabo un comentario sobre la enunciación y el enunciado citados («discurso acerca del discurso... enunciado acerca del enunciado»).

El DR -hemos dicho- es uno de los instrumentos principales de la polifonía textual. Por polifonía textual entendemos, con Ducrot (1986), la pluralidad de

* Catedrático de Lengua española en el Departamento de Lengua española de la Universidad Complutense de Madrid.

1 Este trabajo se encuadra dentro del proyecto Programes 4: «Procesos de gramaticalización en la historia del español (IV): gramaticalización y textualización», referencia FFI2012-31427, financiado por el Ministerio de Economía y Competitividad. 
sujetos del discurso. En todo texto se perciben las voces armonizadas -en el sentido técnico de polifonía musical- de tres sujetos del discurso: el emisor o sujeto empírico (el autor), el locutor o sujeto de lo que se dice en el texto (el yo del texto) y variados enunciadores o «sujetos-puntos de vista» que introduce el locutor y con los que mantiene unas relaciones de mayor o menor distancia. A estos tres sujetos corresponden tres receptores: al emisor, el lector u oyente; al locutor, el alocutario (el tú del texto); y a los enunciadores, los «enunciatarios» o interlocutores "puntos de vista».

Aclarados estos dos conceptos básicos, conviene decir que, desde hace ya algún tiempo, se viene aceptando la necesidad de un enfoque discursivo del DR, incluso en los estudios estrictamente gramaticales (Méndez 2009), pero, por otra parte, los análisis discursivos se olvidan con frecuencia de la sintaxis, cuando -como hemos visto en la misma definición de DR- en la explicación de estas construcciones el esquema sintáctico es pertinente en el máximo grado (discurso y enunciado dentro del discurso y el enunciado).

Prescindir del esquema sintáctico -interoracional, pero también supraoracional e intraoracional- ha llevado a algunas aportaciones recientes (Escribano 2009; Sánchez García 2012) a desatender cuestiones de peso, como:

1) La variabilidad de la relación sintáctica del discurso que cita y el discurso citado, que no se puede reducir a yuxtaposición (DD) y a subordinación sustantiva con función de complemento directo (DI).

2) La combinación de distintas formas del DR -lo que denominé «enunciado pluriforme» (Girón Alconchel 1989: 221-269)- para representar e interpretar los distintos discursos de una misma situación comunicativa o las distintas partes de un mismo discurso.

Con la intención de ofrecer un planteamiento adecuado a estas cuestiones, en lo que sigue me propongo tres objetivos principalmente: 1) mostrar que la sintaxis, aunque no es suficiente por sí misma para explicar el DR, es absolutamente necesaria; 2) desarrollar la definición de DR de Voloshinov con la aplicación de dos nociones: a) la de situación comunicativa de Koch / Oesterreicher (2007) y b) la de cadena de gramaticalización de las relaciones interoracionales (Lehmann 1988; Hopper / Traugott 2003) y su posible continuidad, por un extremo, en las relaciones supraoracionales y, por otro, en las relaciones intraoracionales (Girón Alconchel 2011); y 3) sugerir -a modo de conclusión- que el enunciado de DR puede identificarse con la «unidad de discurso» (Garrido 2007 y 2013), la construcción lingüística que, gobernada por la realización de un determinado efecto retórico, integra una o más oraciones y se configura como la máxima unidad lingüística en la construcción del texto. 


\section{Los enunciados de DR representan e interpretan situaciones comunicativas}

\subsection{Citas explícitas e implícitas}

El locutor del texto puede presentar a sus enunciadores de un modo más o menos definido y explícito. Los enunciadores presentados explícitamente son los sujetos de las citas explícitas, construcciones en las que se manifiesta la «heterogeneidad mostrada en el discurso» (Authier-Révuz 1984). La cita explícita coincide con el enunciado de DR.

Para que haya enunciado de DR el locutor tiene que presentarnos a un enunciador definido -sujeto del discurso citado- y un escenario comunicativo, un exterior del discurso (Authier-Révuz 1984), o sea, una situación comunicativa. Por tanto, el enunciado de DR es una construcción cuyo significado es la representación e interpretación de una situación comunicativa (Vuillaume 1996; Marnette 2005) y cuya forma contiene tres componentes: a) el discurso que cita o marco; b) el discurso citado o cita; y c) la relación sintáctico-semántica del marco y la cita. Esta relación es variable y puede situarse en la relación supraoracional, interoracional o intraoracional. De ahí que la extensión del enunciado de DR pueda variar también desde la secuencia supraoracional a la oración simple, pasando por la oración compuesta.

El enunciador no presentado explícitamente se camufla en las citas implícitas, en la «heterogeneidad constitutiva del discurso» (Authier-Révuz 1984): enunciados irónicos, porque la ironía -como decía el Dr. Johnsones decir dos cosas al mismo tiempo, negaciones y presuposiciones y, sobre todo, empleo de lo que Ducrot denominó "conectores intertextuales»: unas expresiones que conectan el texto de un enunciador no definido con el texto del locutor; son conectores intertextuales las subordinadas de la enunciación (causales, condicionales, concesivas), las adversativas, ciertos marcadores del discurso, como evidentemente, sin duda, por supuesto, el futuro y el condicional de probabilidad, entre otros (Reyes 1994: 40-44). El mundo de las citas implícitas está todavía por explorar completamente. Por eso nos centramos en las citas explícitas, que se manifiestan textualmente en los enunciados de DR.

Sin embargo, las citas explícitas y las implícitas tienen la misma función: modalizar el discurso del locutor (Charaudeau 1992: 622-629) y componer la intertextualidad, uno de los rasgos definidores de la textualidad (Beaugrande / Dressler 1997). Ambos tipos de citas se combinan para representar e interpretar una situación comunicativa. Leamos en (1) el texto de una carta al director del diario El País del escritor Javier Marías:

(1) Muy cerca de mi casa, hoy, día 21, acaba de tener lugar una surrealista batalla campal entre miembros de la Policía Municipal, que se manifestaban en la calle Mayor contra el alcalde, y miembros de la Policía Nacional, que han cargado contra los primeros sin contemplaciones (botes de humo, porras, pelotas de goma). He de deducir que, de paso, la Policía Nacional también ha cargado contra los vecinos de la zona, ya que en mi 
dormitorio, situado en un tercer piso, ha aparecido una de esas pelotas de goma (amarilla y pesada, la tengo ante mí), que algún miembro de ese cuerpo habrá decidido dispararme, por si acaso me daba (nada personal, sin duda). El ministro del Interior debería tal vez advertir a sus fuerzas respecto a la conveniencia de no disparar contra las casas de la población. Y también debería recomendarles que no empleen el cinismo con tanta desfachatez. He bajado con la pelota en cuestión, me he acercado a un mando de la Policía Nacional, le he preguntado si el esférico era suyo, me ha dicho que sí. Y al decirle yo entonces que me explicara cómo diablos la había encontrado en mi alcoba (si llego a estar en el balcón me noquea sin remisión) ha contestado, con un encogimiento de hombros y chulería en el tono: 'Habrá rebotado desde el suelo'. Hasta un tercer piso... Es conveniente que los lectores sepan que los suelos de Madrid son, según la Policía Nacional, un auténtico trampolín’. <http://elpais.com/ diario/2002/02/22/madrid/1014380663_850215.html\#despiece1>

Y observemos en este texto el siguiente enunciado de DI:

He de deducir que de paso, la Policía Nacional también ha cargado contra los vecinos de la zona, ya que en mi dormitorio, situado en un tercer piso, ha aparecido una de esas pelotas de goma (amarilla y pesada, la tengo ante mí), que algún miembro de ese cuerpo habrá decidido dispararme, por si acaso me daba (nada personal, sin duda).

Este DI representa un monólogo en el que el locutor del texto asume el papel de un enunciador que se ve forzado por los hechos y las conjeturas a una deducción. El marco He de deducir presenta al enunciador -el mismo locutor-y su acto comunicativo en forma de monólogo. La cita coincide formalmente con la oración subordinada sustantiva. Entre cita y marco hay, pues, una relación de subordinada sustantiva de complemento directo. Sería un enunciado canónico de DI, si no fuera porque en el discurso citado aparecen citas implícitas:

El conector de intertextualidad causal de la enunciación refuerza el acto de monólogo deductivo del enunciador ('y deduzco esto ya que en mi dormitorio...').

Hay otros dos conectores de intertextualidad: el futuro de probabilidad habrá decidido y la locución conjuntiva por si acaso: que algún miembro de ese cuerpo habrá decidido dispararme, por si acaso me daba. Estos conectores de intertextualidad introducen otra cita implícita que sirve de base a la deducción del enunciador.

La locución conjuntiva por si acaso (por si acaso me daba) funciona de modo semejante a las condicionales de la enunciación del tipo "condicional ilocutiva» y es el producto de la gramaticalización y posterior lexicalización de la preposición por con sentido causal, de la conjunción condicional si (de modo que por si expresa la causa hipotética) y del adverbio de duda acaso (RAE 2009: $\$ \$ 47.2 \mathrm{e}-\mathrm{g}$ y $47.4 \mathrm{e})$.

Esta cita implícita a base de conectores intertextuales muy marcados se continúa con un enunciado irónico entre paréntesis, nada personal, sin duda, que es otra cita implícita. 
¿Quién dice nada personal? ¿El enunciador irónicamente? ¿O tal vez el «enunciatario» o interlocutor del enunciador? ¿O quizá el «alocutario»o interlocutor del locutor? ¿O simplemente el receptor o interlocutor del emisor o autor empírico, o sea, el lector? ¿Y quién de ellos dice sin $d u d a$ ? Porque sin duda es una locución adverbial evidencial que presenta «la veracidad del contenido proposicional como evidente» y que responde a una pregunta de sí o no y adquiere un valor de enunciado en este contexto (RAE 2009: $\$ \$ 30.11$ b y 42.71). Por tanto, es por sí misma, una cita implícita más.

Por último -aunque es lo primero en la secuencia lingüística-, la locución adverbial de paso, con la acepción de 'aprovechando la ocasión' (DRAE, s.v. paso), califica modalmente el predicado del marco de la cita en DI; es decir, manifiesta la opinión y creencia del locutor de que la Policía también ha cargado contra los vecinos y no solo contra los manifestantes. Po lo cual esta cita certifica desde su comienzo su carácter de conjetura un si es no es prejuicio.

Nótese que el significado de de paso muestra cohesión léxica con el significado gramatical del futuro de probabilidad y de las locuciones por si acaso y sin duda.

Fijémonos ahora, dentro del mismo texto (1), en la representación de la siguiente escena:

He bajado con la pelota en cuestión, me he acercado a un mando de la Policía Nacional, le he preguntado si el esférico era suyo, me ha dicho que sí. Y al decirle yo entonces que me explicara cómo diablos la había encontrado en mi alcoba (si llego a estar en el balcón me noquea sin remisión) ha contestado, con un encogimiento de hombros y chulería en el tono: 'Habrá rebotado desde el suelo'. Hasta un tercer piso...

¿Quién dice Hasta un tercer piso...? Desde luego, no el mando de la Policía Nacional. Tampoco parece verosímil que lo diga el enunciador que dialoga con el mando, aunque es probable que lo piense en una especie de monólogo que funciona dramáticamente como un aparte escénico. Pero también lo podríamos atribuir al receptor del texto, al lector. Por eso es una cita implícita, porque no tiene un enunciador definido.

Y también es una cita implícita, porque, además, es un enunciado irónico: lo diga quien lo diga está diciendo otra cosa. Y la cita implícita colabora, en este caso, con las explícitas (DI, discurso directo subordinado² (DDS), [discurso indirecto mimético (DIM) + DD], DD), en la representación e interpretación de la situación comunicativa:

2 Denomino "discurso directo subordinado (DDS)" a lo que en la estilística se denominó "discours direct lié" (Spitzer 1946) o "discorso diretto legato" (Herczeg 1950): o sea, a la forma del DR que representa un fragmento del discurso, como en "Le preguntó que a qué hora deseaba salir, y ella respondió que a las cuatro" (apud RAE 2009: 43.9p), o un discurso implícito en los adverbios pro-oracionales sí y no, como en el ejemplo que estamos analizando, o un enunciado de DD precedido de la conjunción que, como veremos más abajo en (3b). Para la noción de "discurso indirecto mimético (DIM)", cf. J. L. Girón Alconchel (2008 y 2013). 
- Turno DI: He bajado con la pelota en cuestión, me he acercado a un mando de la Policía Nacional, le he preguntado si el esférico era suyo

- Turno DDS: me ha dicho que sí

- Turno DIM (a) + DD (b): (a) Y al decirle yo entonces que me explicara cómo diablos la había encontrado en mi alcoba + (b) (si llego a estar en el balcón me noquea sin remisión)

- Turno DD: ha contestado, con un encogimiento de hombros y chulería en el tono: 'Habrá rebotado desde el suelo'.

- Turno de cita implícita: Hasta un tercer piso...

Por último, veamos una narración oral en (2):

(2) Entonces, escribimos a mis hijos, a mi hijo C. y A., que estaban veraneando en La Granja diciendo que si sería posible encontrarnos unas habitaciones con camas en La Granja, ahora, nosotros haríamos la comida por nuestra cuenta. Tuvimos la suerte de que a los dos días nos llamó por teléfono diciendo que había encontrado una cosa muy buena, y efectivamente, comprometieron la habitación por diez días, y allí nos fuimos a La Granja (El habla de la ciudad de Madrid. Materiales para su estudio, ed. de Manuel Esgueva y Margarita Cantarero, Madrid: CSIC, 1981, p. 235. Habla un hombre de 70 años, militar. Formalidad: baja; audiencia: interlocutor; canal: cara a cara. Las cursivas son mías).

En (2) la conjunción adversativa ahora funciona como conector de intertextualidad: ahora, nosotros haríamos la comida por nuestra cuenta. Conecta esta cita en DIL con la cita implícita, presupuesta en la petición de que les busquen un alojamiento en La Granja: una cita que podría ser 'les vamos a tener que dar de comer' (si el enunciador no definido fueran los hijos) o 'nos van a tener que dar de comer' (si fueran los mismos padres). De este modo la cita implícita marca la transición del DI inmediatamente anterior (la petición) con el DIL que sigue y que es la respuesta explícita a la cita implícita.

\subsection{Las citas explícitas son el DR y representan e interpretan una situación comunicativa}

A pesar de esta relación de cita implícita y cita explícita, nos vamos a centrar en las segundas exclusivamente.

La cita explícita es el DR. Su contenido no es tanto la reproducción de un discurso cuanto la representación e interpretación del mismo dentro de su situación comunicativa: la creación de una imagen sociodiscursiva (Méndez 2009). Para "representar» e «interpretar» un discurso hay que construir una situación comunicativa, que es un acontecimiento integrado por los siguientes parámetros:

a) Grado de publicidad, es decir, el carácter más o menos público de la comunicación, para el que son relevantes el NúMERO DE INTERLOCUTORES (desde el diálogo entre dos hasta la comunicación de masas), así como la existencia de público y sus dimensiones. 
b) Grado de familiaridad entre los interlocutores, que depende de la experiencia comunicativa conjunta previa, del conocimiento compartido, del grado de institucionalización de la comunicación, etc.

c) Grado de implicación EMOcional, que puede estar regida por el interlocutor (afectividad) y/o por el objeto de la comunicación (expresividad).

d) Grado de anclaje de los actos comunicativos en la situación o en la ACCIÓN.

e) CAMPO REFERENCIAL, para el que es decisiva la distancia de los objetos y personas referidas con respecto al origo (ego-hic-nunc) del hablante [...].

f) INMEDIATEZ FÍSICA DE LOS INTERLOCUTORES (comunicación cara a cara) frente a la distancia física en sentido espacial y temporal.

g) Grado de CoOperación, medido según las posibilidades de intervención de los receptores en la producción del discurso.

h) Grado de Dialogicidad, para el que [...] son determinantes la posibilidad y la frecuencia de la asunción espontanea del papel de emisor [...].

i) Grado de ESPONTANEIDAD de la comunicación.

j) Grado de Fijación temática (Koch / Oesterreicher 2007: 26-27).

Estos parámetros -que, como se habrá observado, son graduales: forman un continuum entre un polo positivo y otro negativo- se pueden identificar onomasiológicamente en los textos.

La expresión lingüística de estos parámetros determina que las distintas formas del DR sean construcciones que comprenden un marco de la cita y la cita o discurso citado, además de la relación sintáctico-semántica de marco y cita.

El marco está constituido por los elementos imprescindibles para que haya cita explícita: el enunciador y la indicación de su acto comunicativo. Por ejemplo, en la escena que hemos comentado en (1) he preguntado narra esos dos elementos: el locutor ha asumido el papel de enunciador, se presenta como tal y define su acto comunicativo (una pregunta).

Pero el marco de la cita también está integrado por otros elementos menos necesarios, pero indicadores asimismo de los parámetros que definen la situación comunicativa. Son los «indicios externos»: He bajado con la pelota en cuestión, me he acercado a un mando de la Policía Nacional.

El DI es la subordinada interrogativa propia prototípica, la que reproduce una pregunta (si el esférico era suyo), con la deixis temporal (era) y personal (suyo) propias del mensaje transparente, anclado en el centro deíctico del locutor. La deixis (el eje "yo-aquí-ahora») es el elemento imprescindible para construir la imagen sociodiscursiva. Pero puede haber otros elementos menos necesarios para construir el discurso citado. Son los indicios internos.

En la escena que comentamos percibimos uno de esos indicios en la elección léxica de «esférico». No es muy normal que uno le pregunte a la policía por el esférico para referirse a las pelotas que lanzan para disolver manifestaciones. Nos explicamos luego la "chulería en el tono» del policía. Por tanto, "el esférico» es 
un hecho estilístico, cargado de intención comunicativa y que manifiesta algunos de los parámetros de la situación comunicativa: los grados de familiaridad, implicación emocional y espontaneidad, así como el campo referencial y la inmediatez física de los interlocutores.

El mismo efecto poseen los indicios que tiñen de inmediatez comunicativa el DIM de otro turno del mismo enunciador: «que me explicara cómo diablos la había encontrado en mi alcoba».

\subsection{Pertinencia de la relación sintáctica de marco y cita}

En los estudios sobre el DR se ha descrito con bastante detalle el marco de la cita y la cita misma, pero no se ha atendido del mismo modo a la relación sintáctico-semántica de marco y cita. Y, sin embargo, como hemos señalado ya, si el DR es discurso dentro del discurso y enunciado dentro del enunciado, la relación sintáctico-semántica es esencial.

El mismo método onomasiológico empleado para identificar los parámetros de la situación comunicativa nos permite percibir esta relación, que es muy variada.

El DD es un caso de yuxtaposición con valor de coordinación. Puede deslizarse hacia la relación supraoracional en enunciados de diálogo de mayor o menor extensión en los que se combina el DD canónico y el discurso directo libre (DDL), DD sin verbo de comunicación en el marco, aunque con enunciador explícito.

En cambio, el DI coincidente con una subordinada sustantiva con función de complemento directo es un caso de subordinación prototípica: la cita es un argumento del predicado de comunicación del marco, del que depende sintácticamente y en el que está integrado semánticamente. Pero hay variantes del DI en forma de subordinadas sustantivas complementos del nombre o aposiciones que son menos dependientes sintácticamente y están menos integradas semánticamente.

Por otra parte, entre el DD y el DI hay una zona de discurso mixto (DM) muy mal descrita, precisamente porque, o no se atiende al esquema sintáctico del DR, o se considera que este esquema solo puede ser yuxtaposición o subordinación prototípica.

En el DM se sitúa el DD precedido de la conjunción que (DDS), sean la cita los adverbios pro-oraciones sí o no (3a), sea un enunciado más o menos extenso de DD (3b), sea un fragmento sintáctico de variada extensión (3cde).

(3) a. me ha dicho que sí (véase 1)

b. Otro de los fijos era Julio Segura, buen estudiante y notable activista. Él sostenía que «los de izquierdas debemos ser los mejores, también en los estudios; es la manera de hacernos respetar», y predicaba con el ejemplo (Joaquín Leguina, La luz crepuscular, Madrid: Alfaguara, 2010, p. 173).

c. Lleno de terror se fue a un desierto y comunicó su camino y abstinencia con un santo anacoreta, el cual por disposición del cielo le sacó de aquel engaño diabólico. Díjole que hacía su abstinencia por agradar a Dios. 
Interrogóle el anacoreta que con qué consejo la hacía, y habiéndole dicho que con ninguno, le respondió que era manifiesta tentación del demonio. (Miguel de Molinos, Guía espiritual, ed. de José Ángel Valente, Madrid, Alianza Editorial, 1989, p. 89).

d. Le preguntó que a qué hora deseaba salir, y ella respondió que a las cuatro / y ella respondió: «A las cuatro» (apud RAE 2009: 43.9p).

e. Me contestó que bueno, que no era para tanto (El Mundo, 21/9/1995, apud RAE 2009: 43.9p).

La RAE (2009) considera que las oraciones de (3de) plantean «la cuestión de si los segmentos subrayados constituyen oraciones subordinadas y la de si ejercen la función de objeto directo. Desde el punto de vista de su estructura interna -añade- no son oraciones, pero sí enunciados, ya que presentan un discurso reproducido integrado en la oración principal» (RAE 2009: 43.9p).

En estas palabras se advierte que no está claro qué esquema sintáctico presentan estas construcciones; los fragmentos sintácticos reproducidos «no son oraciones, pero sí enunciados», afirmación de trabajosa digestión, pues -según el mismo texto académico- el enunciado "constituye una unidad de sentido, aunque carezca de verbo, y posee propiedades entonativas distintivas», por ser «la unidad mínima de comunicación» (RAE 2009: $\$ 1.13 f$ ). Un enunciado, pues, tiene entonación autónoma; por eso la Nueva gramática de la lengua española había afirmado unos párrafos antes que «Las oraciones coinciden a menudo con los enunciados, pero las subordinadas no constituyen enunciados por sí solas» (RAE $\$ 1.3 \mathrm{~g}$ ).

En definitiva, si los fragmentos sintácticos reproducidos en (3de) son enunciados - como dice la RAE (2009)- no pueden ser DI -como también dice la misma RAE (2009)-, porque un enunciado tiene entonación autónoma y porque las oraciones subordinadas no pueden ser enunciados por sí solas. Habrá que concluir, pues, que todos los ejemplos de (4) son casos de DD precedidos de la conjunción que, es decir, un esquema sintáctico en el que se solapan coordinación asindética y subordinación y al que podemos llamar DDS. Habrá que concluir que hace falta un esquema sintáctico que supere la dicotomía yuxtaposición / subordinación.

Leamos ahora el ejemplo (4):

(4) Dado que había crecido como varón, no había en sus movimientos nada que la delatara. Sus senos apenas se habían desarrollado; eran pequeños y aplastados; desde antes de la pubertad su madre le había confeccionado un estrecho corpiño para llevar bajo la camisa -se burlaba de ellos llamándolos «sus huevos fritos»-. Según me dijo, no era virgen. Pero ni ella dio más detalles ni yo se los pedí. En retribución, le dije que yo tampoco lo era. Al preguntarle si yo daba la impresión de ser un hombre, me respondió que sí, sólo que al rato añadió riéndose que algunos me consideraban afeminado. Nuestro compromiso de no hablar abiertamente del pasado se compensaba con la franqueza con que compartíamos los asuntos del presente. En nuestras conversaciones nocturnas no ocultábamos las opiniones, pesares, alegrías y problemas que pudiéramos 
tener. Coincidíamos en mucho. Ambas odiábamos la guerra y teníamos inclinaciones republicanas, aunque diferíamos en un importante punto: Fauriel era jacobina. Al serme difícil ocultársela, le hablé de mi clandestina pasión por Bousquet y de mi espionaje junto a la pared que dividía nuestros apartamentos. Esta confesión pareció contrariarla. Para ella Bousquet no sólo carecía de atractivo sino que además era un tonto de capirote. -No me explico cómo ese petimetre te ha hecho perder la cabeza. Eres una mujer inteligente, Fuenmayor.

Estuve tentada de contarle la historia de mi Apolo, pero recapacité... (Antonio Benítez Rojo, Mujer en traje de batalla, Madrid, Alfaguara, 2001, p. 252-253).

Y en este texto de (4) observemos la oración: Para ella Bousquet no sólo carecía de atractivo sino que además era un tonto de capirote. Son palabras del personaje Fauriel: palabras en la mención indirecta, palabras del personaje ancladas en el centro deíctico del locutor, pero con entonación de DD. Lo sabemos, principalmente, porque el discurso citado se continúa, sin solución de continuidad, en la forma de DDL que le sigue: No me explico cómo.... Esta cita está introducida por la preposición para, en un uso que describe perfectamente la RAE (2009), que dice: esta preposición se usa también «para introducir complementos nominales o pronominales que designan a la persona que sostiene cierto parecer. En este caso, para equivale a según, como Para él, yo estoy loco Según él, yo estoy loco» (RAE 2009: \$29.81).

Nótese que «el complemento nominal o pronominal» introducido por la preposición para es el marco de la cita, reducido al enunciador («la persona que sostiene cierto parecer») y que los ejemplos de la RAE son de DD, como también es DD esta oración de (1): los suelos de Madrid son, según la Policía Nacional, un auténtico trampolín. Sin embargo, la oración que comentamos de (2) es DIL, porque la cita queda anclada en el centro deíctico del locutor (transposición pronominal y verbal: Para ella en vez de 'para mí'; era en vez de 'es'), aunque no hay subordinación sustantiva y sí, en cambio, léxico coloquial propio del personaje y del DD, más que del narrador y del discurso narrativo (un tonto de capirote).

En consecuencia, queda claro que esta variante de DIL no coincide con un esquema interoracional, sino intraoracional: ni el marco es una oración principal ni la cita una subordinada o interordinada, sino que el marco es un complemento parentético de la cita y esta una oración independiente. Queda claro también que con este tipo de marco (Para / Según + nombre o pronombre) se pueden construir enunciados de DIL y de DD.

Además de preposición, según puede ser un adverbio relativo con antecedente incorporado que introduce oraciones con verbo en forma personal de sentido modal (RAE 2009: $\$ \$ 22.7 f$ y $29.2 e)$, como en (5abc).

(5) a. Según me dijo, no era virgen (en 4).

b. Huguet criticó ayer el hecho de que los críticos, que, según dijo, «se ha puesto por montera los estatutos del partido», reclamen más democracia interna... (La Vanguardia, 16/11/1995, CREA) 
c. «Compostela e o Camiño viñeron a París a render contas dunha herdanza da que non foron meros beneficiarios pasivos», según dijo el conselleiro de Cultura e Xuventude, Daniel Barata Quintás, en el curso de su intervención en el acto de clausura de las jornadas "Santiago, Camiño de Europa”. (La Voz de Galicia, 23/11/1991, CREA)

d. Como dize Aristótiles, cosa es verdadera, / el mundo por dos cosas trabaja: la primera, / por aver mantenençia; la otra cosa era / por aver juntamiento con fenbra plazentera. (Juan Ruiz (Arcipreste de Hita), Libro de buen amor, 1330-1343, CORDE)

e. ¿Tienes tú el capricho de ser Marquesa? ¿Te gustaría la coronita? En una palabra: ¿es para ti cuestión de ser o no ser, como dijo el otro? (Benito Pérez Galdós, Torquemada en el purgatorio, 1894, CORDE).

Es evidente que las oraciones Según me dijo (5a) y según dijo (5bc) presentan al enunciador y su acto comunicativo y, por tanto, forman parte del marco de las tres citas. Del mismo modo, no era virgen (5a) se identifica con la cita, una cita indirecta, porque la deixis temporal se mide por el centro deíctico del locutor. Pero no es menos cierto que en (5bc), con el mismo esquema sintáctico, la cita es directa, no solo por el entrecomillado, sino porque el eje "yo-aquí-ahora» está anclado en el campo deíctico del enunciador. Incluso en (5c) el DD queda reforzado porque la lengua del discurso citado -el gallego- no es la misma que la del discurso que cita.

Por tanto, estamos ante un esquema sintáctico que no es ni yuxtaposición, ni subordinación, ni oración simple, y con el que se construyen enunciados de DD (5bc) y de una forma de DI que no coincide ni con el DI prototípico ni con ninguna de sus variantes (todas ellas subordinadas sustantivas) ni tampoco con las variantes más representativas del DIL. Podríamos hablar de una forma de discurso mixto (DM), como el ya visto DDS.

Lo dicho para este esquema sintáctico con según vale para el que lleva como, también adverbio relativo de antecedente incorporado (5de).

Las variantes del DIL también reclaman un esquema sintáctico que supere la dicotomía yuxtaposición / subordinación. Sin ánimo de agotar todas las posibilidades, tenemos, en primer lugar, además del ya visto ejemplo de (4) con para, el DIL que continúa un DI previo, una variante existente desde orígenes (6) y con gran vitalidad en todas las épocas y textos, incluidos los textos orales, como hemos visto en (2), con lo que no hace falta insistir en que es doblemente erróneo considerar que el DIL es solo un procedimiento literario y un procedimiento moderno:

(6) e él le dixo dónde era e cómmo se avía asentado sobre la çeniza de mientra trasladara aquellos libros, e cómmo comiera el pan de ordio, e cómmo pasara mucha cueita e mucha lazeria, e trasladó aquellas artes. E después qu'esto le ovo contado... (Sendebar, ed. de María Jesús Lacarra, Madrid, Cátedra, 1989, p. 132. Subrayado mío).

En esta variante la secuencia que sigue al DI -e trasladó aquellas artesadquiere una independencia tonal correspondiente a su menor dependencia 
sintáctica del predicado regente y a su menor integración semántica en el mismo. En (2) ese aflojamiento de la subordinación venía marcado por el conector contraargumentativo ahora, que, además de conectar la cita indirecta libre, con una cita implícita, funcionaba como solución de continuidad entre el DIL y el DI previo. En (6) el aflojamiento de la subordinación -o solapamiento de coordinación y subordinación- se sitúa en la oración e trasladó aquellas artes. ¿Quién dice esto? Naturalmente, el enunciador, como asegura el indicio del marco: E después qu'esto le ovo contado. Estamos, pues, ante una forma de DIL, porque, aunque trasladó esté en el mismo nivel de deixis temporal que dixo, está gobernado semánticamente por este: está integrado en su significado; y, sin embargo, no hay marca de subordinación, sino de coordinación copulativa, como sucede en el DD.

Otra variante del DIL es aquella en la que el discurso citado se yuxtapone al marco de la cita -como en el DD-, pero permanece anclado en el centro deíctico del locutor. Otro caso -quizá el más fulgurante- de solapamiento de coordinación y subordinación:

(7) El viernes 17 de agosto estaba yo almorzando con Miriam, y su marido, Arturo, se nos sumó. Traía malas noticias. El general Ruiz, ministro de Transportes, acababa de dimitir ante Allende. El presidente le había aceptado la dimisión con una condición: que dimitiera también de comandante en jefe de la Fuerza Aérea y pasara a retiro. El general se había negado.

A mediados de agosto fui con los Aspún a su casa de Concón... (Joaquín Leguina, La luz crepuscular, Madrid, Alfaguara, 2010, p. 320-321).

En (7), a partir de su marido, Arturo, se nos sumó, escuchamos la voz del enunciador Arturo dentro de la voz del locutor y dentro de ellas las voces del general y del presidente que acepta la dimisión con una condición. (Nótese que el locutor diría 'con la condición'.) Este es un enunciado pluriforme, un enunciando con distintas formas de DR -DIL y «discurso narrado» ${ }^{3}$ (DN)que se combinan para representar e interpretar distintas intervenciones de distintos enunciadores en dos situaciones comunicativas también distintas: la conversación en el restaurante entre Arturo, su mujer Miriam y el locutor narrador y la conversación en el despacho del presidente de la República entre este y el general Ruiz:

- Turno único de Arturo en DIL: Traía malas noticias. El general Ruiz, ministro de Transportes, acababa de dimitir ante Allende. El presidente le había aceptado la dimisión con una condición: que dimitiera también de comandante en jefe de la Fuerza Aérea y pasara a retiro. El general se había negado.

3 Entendemos por enunciado de «discurso narrado (DN)» aquel en el que el discurso citado no es una oración, sino el argumento -complemento directo o complemento de régimen preposicional- del predicado que se identifica con el discurso que cita (dijo una tontería, habló de fútbol), o incluso con un rasgo semántico de dicho predicado (se había negado, protestó). Cf. Girón Alconchel (2008 y 2013). 
- Turno del general Ruiz representado en el discurso de Arturo en DN: El general Ruiz, ministro de Transportes, acababa de dimitir ante Allende.

- Turno del Presidente Allende representado en el discurso de Arturo en DIL: El presidente le había aceptado la dimisión con una condición: que dimitiera también de comandante en jefe de la Fuerza Aérea y pasara a retiro.

- Turno del general Ruiz representado en el discurso de Arturo en DN: El general se había negado.

Otra variante de DIL es la de verbo performativo o delocutivo:

(8) a. Zapatero promete que si hay crisis protegerá a los débiles más que el PP ( $E l$ País, 11-2-08) (apud Escribano 2009: 30).

b. Solchaga prometió que el PSOE dará rápida respuesta a la corrupción $(\mathrm{Ya}$, 20/04/1994) (apud Sánchez García 2012: 7)

c. El PP promete a los parados de más de 45 años 350 euros al mes si aceptan empleos (El Mundo, 11-3-04) (apud Escribano 2009: 30)

d. Zapatero promete el 5\% del empleo público para discapacitados y el «déficit cero» en sus derechos (La Razón, 11-3-04) (apud Escribano 2009: 30)

e. FAES exige al PSOE que retire una foto suya de Aznar por su utilización «abusiva» (ABC, 23-2-08) (apud Escribano 2009: 29)

f. Clinton acusa a Obama de pregonar un mensaje vacío (El País, 16-2-08) (apud Escribano 2009: 22)

g. El gobierno y el PP acusan al PSOE del acoso y la violencia contra sus sedes (ABC, 14-3-04) (apud Escribano 2009: 22)

h. Rajoy felicita a Zapatero y se pone al servicio del PSE en la lucha contra el terrorismo (La Razón, 14-3-04) (apud Escribano 2009: 31).

Estos verbos significan hacer lo que se hace cuando se dicen, o sea, hacer un acto por decir el acto. Por ejemplo, prometer significa decir 'yo prometo'. Tienen un uso realizativo en primera persona del presente de indicativo y un uso descriptivo en otra persona y tiempo. Usados realizativamente efectúan el acto lingüístico que significan; al decir yo prometo, realizo el acto de prometer, hago una promesa. Empleados descriptivamente no realizan el acto lingüístico, pero lo reproducen porque no llegan a perder totalmente su fuerza ilocutiva, de modo que Zapatero promete que si hay crisis protegerá a los débiles... (8a) significa 'Zapatero dice que promete que si hay crisis protegerá a los débiles...'; y Solchaga prometió que el PSOE dará rápida respuesta a la corrupción (8b) vale 'Solchaga dijo que prometía que el PSOE daría rápida respuesta a la corrupción', y El PP promete a los parados de más de 45 años 350 euros al mes... es igual que 'El PP dice que promete a los parados de más de 45 años 350 euros al mes...' (8c).

Lo mismo se puede decir en (8efg) de exigir y acusar (Ducrot 1980; Anscombre 1982 y 1985; De Brabanter 2005; Casado Velarde 2010). Mediante estos verbos, usados descriptivamente, el locutor realiza una autonimia ${ }^{4}$ :

4 Una buena definición de autonimia es esta: «It is in essence a discourse phenomenon that consists in using a word, phrase, sentence, not with its ordinary denotation, but in order to highlight that word, phrase or sentence itself, or some relevant linguistic aspect of it» (De Brabanter 2005: 171). 
menciona y usa el lenguaje, al mismo tiempo (cf. Authier-Revuz et al. (eds.) 2003; De Brabanter 2005; Vigo 2012).

Así pues, los verbos delocutivos -prometer, exigir, acusar, y otros: pedir, recomendar, etc.-, por un lado, no forman parte del marco de la cita, en sentido estricto, sino del discurso citado; pero, por otro, se comportan como verbos del marco, o discurso que cita, en cuanto que pueden regir un complemento indirecto o directo cuyo referente es el interlocutor de la cita, o sea, un indicio externo del marco: promete a los parados de más de 45 años (8c), exige al PSOE (8e), acusa a Obama (8f), acusan al PSOE (8g). En estos verbos se mezclan -o armonizan- las voces del locutor y de su enunciador. Por eso son DIL.

El marco de la cita queda reducido en estos enunciados de DIL a la mención del enunciador y, como acabamos de decir, en algún caso (8cefg), a la de su interlocutor; y la cita o discurso citado se identifica con el verbo delocutivo de la oración principal y sus complementos -oracionales (8abef) o nominales (8cdg)-, con su entonación autónoma: es un modo de poner la cita en un escenario propio de oración independiente, no de subordinada, de núcleo sintáctico, no de margen; en un escenario de autonomía sintáctica y semántica, similar al de la cita en DD.

Por su parte, el discurso citado se organiza en torno al centro deíctico. El centro deíctico puede ser el del enunciador, al que se traslada el locutor, un hecho no infrecuente en el DI, que asegura el continuum de DI y DIL. Así, en la deixis temporal, aceptan (8c), exige que retire (8e) o promete que si hay crisis protegerá a los débiles (8a), o, más evidente aún, por el contraste con el tiempo del predicado regente: prometió que dará (8b), no 'que daría', como pide el DI canónico. En cambio, la deixis espacial se organiza desde el centro deíctico del locutor: sus derechos (8d), foto suya, su utilización (8e), sus sedes (8g).

También descubrimos indicios internos de reproducción en estas citas indirectas libres: el período condicional de la enunciación (8ac), que remite a una cita implícita y, por tanto, añade una voz más a la polifonía textual, y las comillas de «déficit cero» (8d) y «abusiva» (8e), que indican autonimia, uso y mención de un término clave.

La relación de marco y discurso citado se identifica con una relación intraoracional: la del sujeto (el enunciador) con el predicado de la oración (el discurso citado). El no percibir esta relación sintáctica del marco y la cita en el conjunto del enunciado de DR y el confundir esta relación intraoracional con la interoracional propia de la subordinación sustantiva les hace decir a Escribano (2009) y a Sánchez García (2012) que los ejemplos de (8) son de DI, pero no lo son, claro. Son enunciados de DIL. La oración compleja de prometer o de exigir (8abe), con su subordinada sustantiva, en su totalidad, es discurso citado, por tanto no es DI; y, además, el complemento del verbo delocutivo puede ser un complemento directo nominal, como en ( $8 \mathrm{~cd}$ ), o un complemento de régimen preposicional, como en ( $8 \mathrm{fg})$. Ni siquiera hay subordinación sustantiva en estos ejemplos. 
Algo parecido sucede con ciertos verbos y ciertas expresiones cuyo empleo significa también uso y mención de la lengua. Son verbos y expresiones que reproducen actos locutivos, aunque no ilocutivos. Por eso han sido denominados verbos «decitativos» (de Brabanter 2005; Casado Velarde 2010) o, simplemente, "citativos» (Anscombre 1985). Su significado también puede parafrasearse por 'decir que X'. A veces se combinan con los verbos delocutivos. En (8h) felicita es un verbo delocutivo; significa 'Rajoy dice que felicita a Zapatero', porque felicitar es un acto lingüístico, con su acto ilocutivo correspondiente. Pero no está claro que ponerse al servicio de alguien sea un acto lingüístico; más bien es un ofrecimiento, sin acto ilocutivo por el que puedan pedirse responsabilidades. Ahora bien, la expresión se reitera -como acto locutivo- en situaciones como las del ejemplo, de modo que puede interpretarse como una expresión decitativa y parafrasearse como 'y dice que se pone al servicio del PSE en la lucha contra el terrorismo'. O sea, felicita (...) y se pone al servicio del PSE no son verbos del marco de la cita, sino verbos del discurso citado: el primero, delocutivo, reproduce un acto lingüístico completo, con su componente ilocutivo; el segundo (la locución ponerse al servicio de alguien), decitativo, reproduce un acto locutivo muy frecuente en situaciones de ofrecimiento. No estamos ante un enunciado de DI, como cree Escribano (2009) por no atender como es debido a la relación sintáctica de marco y cita, sino ante un enunciado de DIL.

Una frase como Traía malas noticias en (7) puede considerarse también decitativa: el locutor no puede decirla si no ha oído antes a su enunciador decir «Traigo malas noticias», por cierto, una frase muy frecuente en el exordio de la narración de una mala noticia. Esta expresión decitativa funciona en (7) como indicio interno de reproducción en el DIL, que adopta la variante sintáctica de la yuxtaposición de marco y discurso, como sucede en el DD, pero con un discurso anclado en el campo deíctico del locutor.

Finalmente, hay un enunciado de DR al que ni las gramáticas ni los análisis del discurso periodístico suelen atender: el enunciado de DN.

(9) a. Aznar y Acebes insisten en apuntar a ETA y la banda lo desmiente (El País, 13-3-04) (apud Escribano 2009: 20)

b. PSOE e IU insinúan un complot urbanístico (La Razón, 12-6-03) (apud Escribano 2009: 20)

c. se burlaba de ellos llamándolos «sus huevos fritos» (4)

d. El general Ruiz, ministro de Transportes, acababa de dimitir ante Allende (7)

e. El general se había negado (7)

En todos los ejemplos de (9) se puede percibir un marco (enunciador y exterior del discurso) y un discurso citado; pero este queda reducido a una oración de infinitivo: apuntar a ETA en (9a), a un sintagma nominal: un complot urbanístico (9b), «sus huevos fritos» (9c), incluso a un verbo que, además de indicar el acto lingüístico del enunciador, sugiere sus componentes locutivos e incluso ilocutivos: dimitir (9d), negarse (9e). En «sus huevos fritos» (9c) la deixis espacial es del locutor y las comillas son solo indicadoras del uso autonímico 
del sintagma nominal. Si el locutor -que asume el papel de enunciador en este ejemplo- hubiese querido reproducir esa pequeña cita de su interlocutor en $\mathrm{DD}$, habría escrito "se burlaba de ellos llamándolos "mis huevos fritos"», no "sus huevos fritos". En todos estos casos el enunciado de DN -no de DI, como cree Escribano (2009) que son los ejemplos de (9ab)- coincide con una oración simple, que, naturalmente, puede coordinarse con otra para componer un enunciado complejo de DN, como en (9a).

\section{La gramaticalización de la relación del discurso que cita y del discurso citado y el enunciando de DR}

Hemos visto que el esquema sintáctico que regula la relación del marco de la cita y el discurso citado tiene dos formas prototípicas de relación interoracional: el DD o esquema de coordinación asindética y el DI prototípico o esquema que coincide con la subordinación sustantiva prototípica. Entre esos dos prototipos hay diversas variantes.

En primer lugar, las variantes del DD que van desde el esquema interoracional a complejos enunciados de diálogo con variadas formas de DDL y extensión supraoracional muy variada.

En segundo lugar, las variantes intermedias entre el DD prototípico y el DI prototípico: el DDS; el DM cuyo marco se organiza en torno a las preposiciones para y según (con variantes de DD y de DIL); el DM cuyo marco son oraciones modales encabezadas por los adverbios relativos de antecedente incorporado según y como; las diversas variantes del DIL más codificado, como a) el DIL que prolonga un discurso reproducido por DI o DIM; b) la cita indirecta libre yuxtapuesta a su marco como los enunciados de DD; y c) el DIL de verbos delocutivos y decitativos; y, ya solapado con el DI prototípico, el DIM, como ese al decirle yo entonces que me explicara cómo diablos la había encontrado en mi alcoba (1).

En tercer lugar, las variantes que van del DI prototípico a la mera alusión narrativa a un discurso: el DI de oración de infinitivo, el DN y el verbo de comunicación que por sí solo sugiere la representación de un discurso en su contenido e incluso su textura verbal, como dimitir, por ejemplo.

El esquema sintáctico del DR es pertinente «más allá» de la oración, pero también «más arriba», porque sus constituyentes -el marco y la cita- pueden ser oraciones, segmentos superiores a la oración y segmentos inferiores.

La cadena de gramaticalización de las relaciones interoracionales nos parece un instrumento adecuado para dar cuenta de esta variedad de relaciones sintácticas. Entre la coordinación -el escenario en que las oraciones relacionadas son núcleos, con una no dependencia sintáctica y una no integración semántica plenas- y la subordinación prototípica -el escenario en el que la oración subordinada es un margen de la principal, un constituyente con una dependencia sintáctica y una integración semántica plenas- hay un estadio intermedio: la 
interordinación, un escenario en que las dos oraciones -o grupos de oracionesdel período mantienen una relación sintáctica de interdependencia y de integración semántica de grado medio.

La cadena coordinación > interordinación > subordinación es un continuum categorial y diacrónico, como todas las cadenas de gramaticalización: una categoría prototípica entre cuyos eslabones se da solapamiento (la permanencia de la construcción desinente en la emergente en tanto se mantiene el proceso de gramaticalización). Por eso resulta un instrumento adecuado para explicar las diversas formas de los enunciados de DR y sus variantes. La coordinación (asindética o yuxtaposición) es el reino del DD; la subordinación prototípica, el del DI canónico; y la interordinación, el del DM, que integra las variantes intermedias entre DI y DD, siendo el DIL la más desarrollada en lo textos y la más codificada en las gramáticas, pero no la única, como demuestran el DDS y el DM de según y para, de según y como y el DIM.

Sin embargo, los pasajes de DD en enunciados de diálogo -a veces muy extensos en los textos narrativos, a los que en el Esquema 1 llamo «Drama»- y el DN exigen que extendamos la cadena de gramaticalización de las relaciones interoracionales a las relaciones supraoracionales, por un extremo, y a las relaciones intraoracionales, por otro, de modo que esta extensión permite dar cuenta de la categoría lingüística del DR, una categoría textual, no ya oracional, como se ve en el esquema 1 :

Esquema 1. La categoría lingüística del discurso referido

\begin{tabular}{|l|l|l|l|l|}
\hline \multicolumn{1}{|c|}{ Drama } & \multicolumn{1}{|c|}{ DD } & $\begin{array}{c}\text { DM } \\
(\mathrm{DIL} \rightarrow) \\
(<\mathrm{DDS})\end{array}$ & DI & \multicolumn{1}{c|}{ DN } \\
\hline Texto & Coordinación & Interordinación & Subordinación & $\begin{array}{l}\text { Constituyente, } \\
\text { rasgo sémico }\end{array}$ \\
\hline & $\begin{array}{l}\text {-Dependencia } \\
\text {-Integración }\end{array}$ & $\begin{array}{l}\text { +/-Dependencia } \\
+/ \text {-Integración }\end{array}$ & $\begin{array}{l}\text { +Dependencia } \\
\text { +Integración }\end{array}$ & $\begin{array}{l}\text { Relaciones } \\
\text { intraoracionales }\end{array}$ \\
\hline $\begin{array}{l}\text { Relaciones } \\
\text { supraoracionales }\end{array}$ & \multicolumn{3}{|c|}{ Relaciones interoracionales } &
\end{tabular}

Las manifestaciones textuales de esta categoría se identifican onomasiológicamente porque se parte desde su significado (la representación e interpretación de una situación comunicativa) para llegar a su forma: a) un marco -con dos elementos imprescindibles: la presentación de un enunciador y de un escenario del discurso-, b) una cita y c) una relación sintáctico-semántica (supraoracional, interoracional o intraoracional) de marco y cita.

Pero lo más frecuente es que el enunciado de DR no contenga una sola forma, sino varias combinadas, es decir, que sea un enunciado pluriforme o un enunciado de diálogo, porque las situaciones comunicativas que se representan e interpretan comprenden varias intervenciones o discursos y los discursos varias partes, que se analizan y comentan, entre otros procedimientos, por la combinación de formas del DR. El enunciado pluriforme y el enunciado 
de diálogo son el hábitat natural del DR. Lo podemos ver en los textos de Marías (1), Benítez Rojo (4), Leguina (7), en el titular de un periódico (9a) e incluso en la lengua hablada (2).

La delimitación del enunciado de DR viene dada por las dos notas definitorias de cualquier enunciado, definido como unidad del texto, según Ducrot (1986): la cohesión y la autonomía. Y es precisamente la identificación onomasiológica de la situación comunicativa que se representa e interpreta el factor que proporciona las claves para reconocer la cohesión (léxica y gramatical) y la autonomía del enunciado. De este modo el enunciando de DR es la unidad textual cuyo significado es la creación de una imagen sociodiscursiva completa: «discurso dentro del discurso y discurso acerca del discurso, enunciado dentro del enunciado y enunciado acerca del enunciado» (Voloshinov 1976: 143).

\section{A modo de conclusión: el enunciado de DR como unidad de discurso en la construcción lingüística del texto}

Hemos visto que el enunciado de DR es una unidad por su cohesión y por su autonomía. La función de esa unidad es crear un efecto retórico, sustanciado en la propia cita como discurso dentro del discurso y acerca del discurso. De este modo el enunciado de DR coincide cabalmente con la unidad de discurso definida por Garrido (2007, 2011). El «texto» es algo más que un producto lingüístico; se relaciona con la trasmisión de una acción social. Un contrato de compraventa es un texto: lo materialmente lingüístico -lo que llamamos «texto» con frecuencia - es solo una parte de esa acción social. Y lo mismo cabe decir de una carta al director de un periódico, o de una novela, o de una autobiografía, o de un turno oral, o de un cantar de gesta, etc. Con palabras de Garrido (2007: 149): «El texto se conecta cognitivamente con la representación de la acción social de la que forma parte» $y$ «es, por tanto, una estructura de [unidades de discurso] integrada en una acción social».

El texto se compone de unidades de discurso; las unidades de discurso, de oraciones; las oraciones, de sintagmas; los sintagmas de palabras. $\mathrm{He}$ ahí, las unidades de la creación lingüística del texto. La gramaticalización de las relaciones interoracionales, con su proyección hacia las relaciones supraoracionales, por un extremo, y hacia las relaciones intraoracionales hacia los sintagmas y las palabras-, por otro, es un instrumento teórico y metodológico que se suma eficazmente a la construcción lingüística del texto. $\mathrm{Y}$, en esta conjunción de gramaticalización de las relaciones interoracionales y de unidad de discurso, el enunciado de DR que aquí hemos explicado coincide con precisión suficiente con una unidad de discurso. Desde este punto de vista cobra pleno sentido sostener que los textos se componen de citas... entre otras unidades de discurso; y que las citas - los enunciados de DR - son genuinas unidades de la construcción del texto. 


\section{Bibliografía}

Anscombre J.C.,1982, «Indicatori e iperindicatori di derivazione illocutiva», in: S. Airoldi et al., La lingua attivata. Pragmatica, enunciazione, discorso, Milano, Franco Angeli Editore, p. 121-163.

Anscombre J.C., 1985, «De l'énonciation au lexique: mention, citativité, délocutivité», Langages, 80, p. 9-34.

Authier-Révuz J., 1984, «Hétérogénéité(s) énonciative(s)», Langages, 73, p. 98-111.

Authier-Revuz J. et al. (ed.), 2003, Parler des mots. Le fait autonymique en discours, Paris, Presses Sorbonne Nouvelle.

Authier-Révuz J., 2003, «Avant-Propos», in: Authier-Revuz et al., p. 7-17.

Beaugrande R. A. y Dressler W.U., 1997, Introducción a la lingüística del texto. Versión española y estudio preliminar de Sebastián Bonilla, Barcelona, Ariel.

Casado Velarde M., 2010, «Discurso y creación léxica: delocutivos y decitativos en español», Revista de Investigación Lingüística, 13, p. 65-85.

Charaudeau P., 1992, Grammaire du sens et de l'expression, Paris, Hachette.

Charlent M. Th., 2003, «L'autonymie dans le discours direct», in: Authier-Revuz et al. (ed.), p. 153-161.

De Brabanter Ph., 2005, «The Impact o Autonymy on the Lexicon», Word LVI/2, p. 171-200.

DRAE = Diccionario de la lengua española $<$ http://lema.rae.es/drae/?val=cita $>$.

Ducrot O., 1980, «Pragmatique linguistique: II. Essai d'application: mais -les allusions à l'énonciation- délocutifs, performatifs, discours indirect», in: H. Parret et al., Le langage en contexte. Études philosophiques et linguistiques de pragmatique, Amsterdam, John Benjamins, p. 487-575.

Ducrot O., 1986, El decir y lo dicho. Polifonía de la enunciación, Barcelona-Buenos Aires-México, Eds. Paidós.

Escribano A., 2009, Las voces del texto como recurso persuasivo, Madrid, Arco/ Libros.

Garrido J., 2007, «Construcción de discurso en noticias de prensa», Revista Española de Lingüística (RSEL), 37, p. 139-168.

Garrido J., 2013, «Evolución de la construcción del discurso en el ensayo entre 1648 y 1726», in: Trabajos de semántica y pragmática históricas. Aportación al estudio de nuevos métodos, ed. de Alicia Puigvert Ocal y Silvia Iglesias Recuero, Madrid, Editorial Complutense, p. 55-94.

Girón Alconchel J.L., 1989, Las formas del discurso referido en el «Cantar de Mio Cid», Madrid, Real Academia Española.

Girón Alconchel J.L., 2008, «Tradiciones discursivas y gramaticalización del discurso referido en el Rimado de Palacio y las Crónicas del Canciller Ayala», in: Sintaxis histórica del español y cambio lingüístico: Nuevas perspectivas desde las Tradiciones Discursivas, ed. de Johannes Kabatek, Madrid, Iberoamericana / Frankfurt am Main, Vervuert, p. 173-196. 
Girón Alconchel J.L., 2011, «Ilativas, interordinación y consecutivas de enunciación», in: Bustos Tovar J.J. et al., Sintaxis y análisis del discurso hablado en español. Homenaje a Antonio Narbona, I, Sevilla, Universidad de Sevilla, p. 551-566.

Girón Alconchel J.L., 2013, «El discurso indirecto y sus variantes en el Sendebar», Crisol. Nouvelle Série, 18, p. 93-133.

Herczeg G., 1950, «Il 'discorso diretto legato’ in Renato Fucini», Lingua Nostra, XI, p. 39-42.

Hopper P.J. y Traugott E.C., 2003, Grammaticalization, 2a ed., Cambridge, Cambridge University Press.

Koch P. y Oesterreicher W., 2007, Lengua hablada en la Romania: español, francés, italiano, Madrid, Gredos.

Lehmann Ch., 1988, "Towards a typology of clause linkage», in: Haiman J., Thompson S.A. (eds.), Clause combining in grammar and discourse, Amsterdam/Philadelphia, John Benjamins, p. 181-225.

Marnette S., 2005, Speech and thought presentation in French, Amsterdam/ Philadelphia, John Benjamins.

Méndez García de Paredes E., 1999, «Análisis de la reproducción del discurso ajeno en los textos periodísticos», Pragmalingüistica, 7, p. 99-128.

Méndez García de Paredes E., 2000, «La literalidad de las citas en los textos periodísticos», Revista Española de Lingüística (RSEL), 30, p. 147-167.

Méndez García de Paredes E., 2000, «Análisis de las formas de introducir el discurso ajeno en los textos periodísticos: el contexto reproductor», in: J. J. de Bustos et al. (eds.), Lengua, discurso, texto (I Simposio Internacional de Análisis del Discurso), Madrid, UCM / Visor, vol. II, p. 2081-2098.

Méndez García de Paredes E., 2009, «Los enunciados de discurso referido y la gramática», in: M.V. Camacho Taboada et al. (eds.), Estudios de Lengua Española: Descripción, variación y Uso. Homenaje a Humberto López Morales, Madrid/ Frankfurt am Main, Iberoamericana/Vervuert, p. 483-517.

Mocher M. A., 2003, «Mention et/ou usage: discours direct et discours direct libre en situation de type conversationnel», in: Authier-Revuz et al., p. 163-174.

Piatti G., 2011, «La estilización: otro aspecto de la modalidad discursiva», Plurentes. Artes y Letras, 0/1, p. 1-14.

RAE = Real Academia Española, 2009, Nueva gramática de la lengua española, Madrid, Espasa Libros.

Reyes G., 1994, Los procedimientos de cita: citas encubiertas y ecos, Madrid, Arco/Libros.

Sánchez García F. J., 2012, El discurso referido en la prensa española, Barcelona, Octaedro.

Spitzer L., 1946, «Sur le discours direct lié (DDL)», Bulletin Linguistique (Bucarest), XIV, p. 19-77. 
Vigo E. M., 2012, «Una nueva mirada a los delocutivos», Revista de Investigación Lingüística, 15, p. 269-292.

Voloshinov V.N., 1976, El signo ideológico y la filosofía del lenguaje, Buenos Aires, Nueva Visión.

Vuillaume M., 1996, «Les varietés de discours indirect libre», Travaux du Cercle linguistique de Nice, 18, p. 51-65. 